\title{
Erratum to: Incidentally found giant thymomas by SPECT myocardial perfusion imaging
}

\author{
Ayman A. Farag, MD, a and Fadi G. Hage, MD, FASH, FACC ${ }^{\mathrm{a}, \mathrm{b}}$ \\ ${ }^{a}$ Division of Cardiovascular Disease, Department of Medicine, University of Alabama at \\ Birmingham, Birmingham, AL \\ ${ }^{\mathrm{b}}$ Section of Cardiology, Birmingham Veterans Affairs Medical Center, Birmingham, AL
}

doi: $10.1007 / \mathrm{s} 12350-015-0189-1$

\section{ERRATUM TO: J NUCL CARDIOL 2015;22:385-7 \\ DOI: 10.1007/S12350-014-0028-9}

Figure 1 was distorted during production and appears distorted in the published article. The corrected Figure 1 appears below.

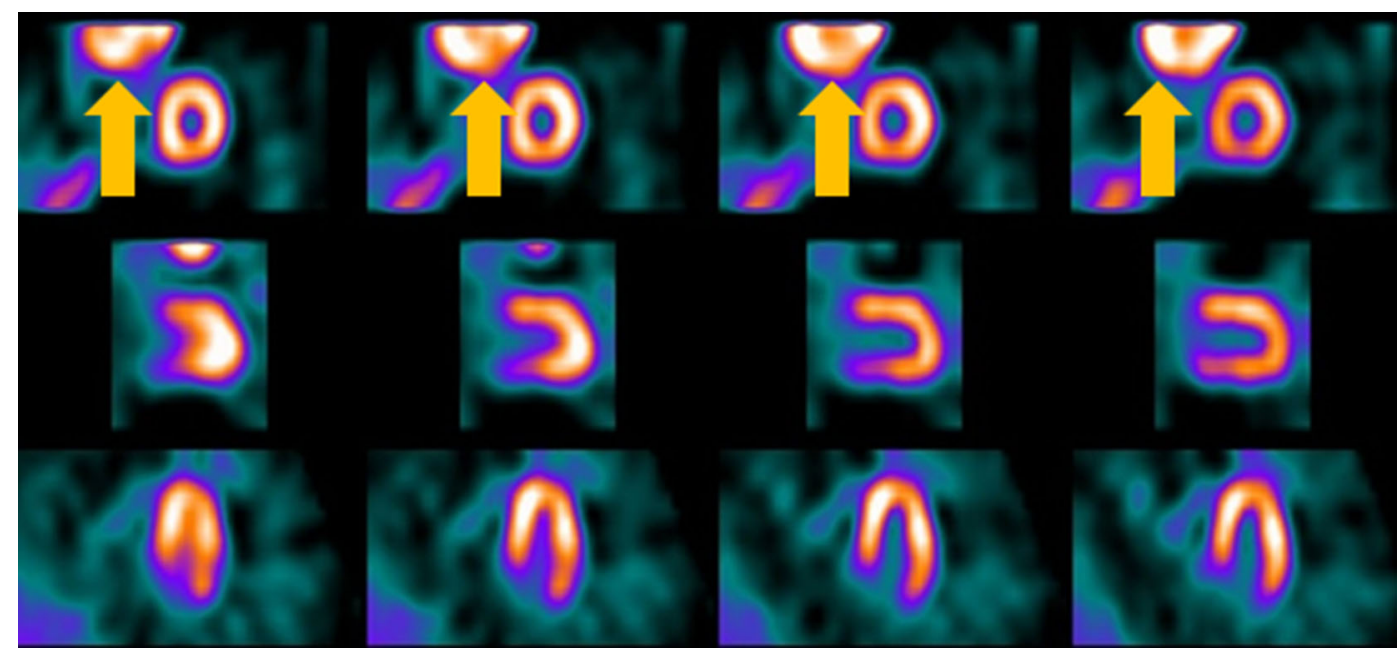

Figure 1. Case 1. Stress Tc-99m sestamibi SPECT images showing normal myocardial perfusion. There is an extracardiac mass seen in the short-axis slices (arrows).

The online version of the original article can be found under doi:10.1007/s12350-014-0028-9.

Reprint requests: Ayman A. Farag, MD, Division of Cardiovascular Disease, Department of Medicine, University of Alabama at Birmingham, THT 311, 1900 University Blvd, Birmingham, AL 35294; afarag@uab.edu

J Nucl Cardiol 2015;22:786.

$1071-3581 / \$ 34.00$

Copyright (c) 2015 American Society of Nuclear Cardiology. 